\title{
Does Type of Dissection for Skin And Subcutaneous Tissue Affect Wound Outcome???
}

\author{
Prathibha B Naik ${ }^{1}$, Sunil Kumar Shetty ${ }^{2}$, Sri Ram Bhat $\mathrm{M}^{3}$, Ashwin Kumar $\mathrm{C}^{4}$, \\ PavanChandar Dudde ${ }^{5}$ \\ ${ }^{\text {I}}$ (Senior Resident, General Surgery, Kasturba Medical College-Manipal University, India) \\ ${ }_{2}^{2}$ (Associate Professor, General Surgery, Kasturba Medical College-Manipal University, India) \\ ${ }_{3}^{3}$ (Professor, General Surgery, Kasturba Medical College-Manipal University, India) \\ ${ }^{4}$ (Senior Resident, General Surgery, Kasturba Medical College-Manipal University, India) \\ 5 (Senior Resident, General Surgery, Kasturba Medical College-Manipal University, India)
}

\begin{abstract}
:
Introduction: Choice of dissection scalpel versus electrosurgery for skin and subcutaneous tissue has been always a topic of debate. We in this study have aimed to compare the wound outcomes following both.

Aims :Compare the wound outcome following scalpel versus electrosurgery incision for skin and subcutaneous tissues in all major abdominal surgeries, hernia repairs and thyroid surgeries.

Methods and Materials: Prospective comparative study conducted in a tertiary teaching hospital from October 2013 to October 2015. Patients undergoing scalpel and electrosurgical dissection were compared in postoperative period for wound outcomes and data recorded. Statistical analysis was conducted using Chi Square Test and p-value calculated.

Results: Sample size of 110 patients were studied in each group and followed up for wound outcome on Day 3,5 and 10 for erythema formation, serous discharge, purulent exudate and separation of deeper tissues. There was significant occurrence of erythema formation and serous discharge among the study groups but there was no statistically difference between the two groups. There was no significant occurrence of purulent exudate and separation of deeper tissues among the study groups.

Conclusions: Results of the study showed there is no significant difference in postoperative wound infection rate or scar cosmesis in scalpel and electrosurgery group. Hence it is the surgeon choice to choose scalpel or electrosurgical dissection for skin and subcutaneous tissue.
\end{abstract}

Keywords: Scalpel, Electrosurgery, Skin and Subcutaneous dissection, Wound complications.

\section{Introduction}

Conventionally, scalpels with disposable knives are used to make surgical skin incisions. But these skin incision are bloody and painful[1].Electrosurgery got introduced during beginning during the beginning of 20th century electrosurgery got introduced to overcome the drawbacks of scalpel [2-4].Electrosurgery is measured as an effective method of dissection $[4,5]$ which is haemostatic also convenient $[4,6]$. Present day electrosurgical units are gaining popularity since they are able to deliver pure sinusoidal current leading to faster haemostasis, quicker dissection and lesser blood loss during surgery [7-9].

In Electrosurgery, potential gradient dependent current passes at very high frequency (more than $100000 \mathrm{~Hz}$ ) through the tissue and it excites molecules within tissue like water causing controlled tissue lyses ,thereby coagulates (modulated mode) or cuts (sinusoidal mode) the tissue. This principle is been made use in electrosurgery electrode without causing harm to surrounding tissue [4,10]. Electrosurgery incision is actually not a real cutting incision [9-11[. In electrosurgery within the tissue, cells get heated up very rapidly and vaporize, leaving a cavity inside the cell matrix and this generated heat gets disappeared as steam, instead of getting transformed to adjacent tissue. With the forward movement of electrode new cells get contacted and are vaporized, thus creating an incision .Thus absenteeism of scaring and consequent healing with minimal scarring can be explained $[9,11$.

Inspite of the advantages, using diathermy for skin and surgical incision as 'cutting' instrument has been denied by most of the surgeons due to the worry of delay in healing of wound and also the threat of infection [4, 9, 11[.To add on some animal data shows increased problems with infection and healing of wound. Contrary to it early case series have provided safety evidence with electrosurgery for skin incision.

The aim of this study is to determine safety and effectiveness of electrosurgery as an alternative to conventional scalpel incision for skin and subcutaneous tissue in all major abdominal surgeries, thyroid surgeries and hernia surgery. Which shall benefit supporting use of electrosurgery and minimize surgical exposure to HIV infected patients, hepatitis $\mathrm{C}$ and hepatitis. 
Aims

Aim of the study is to compare the wound outcome following scalpel dissections versus electrosurgery for skin and subcutaneous tissue in all major abdominal surgeries, hernia repairs, and thyroid surgeries.

The wound outcome was measured in terms of erythema, serous discharge, purulent exudate and separation of deep tissues. The study also compared the isolation of bacteria in both study groups and hospital stay more than fourteen days as a result of wound infection was also compared in the study groups.

\section{Materials and Methods}

The study was a prospective descriptive study conducted in tertiary teaching hospital on patients from October 2013 - October 2015. The total sample size for the study was 220 patients divided in two groups. Group A includes patients who underwent scalpel dissection for skin and subcutaneous tissue Group B includes patients who underwent electrosurgery dissection for skin and subcutaneous tissue5. All male and female patients above 18yrs of age undergoing abdominal surgeries, hernia and thyroid surgeries were included in the study. Patients less than $18 y$ rs of age were excluded from the study.

Institutional ethics committee approval and informed written consent from patients were obtained. Skin incision made and subcutaneous layer dissection was done using scalpel in group A and using electrosurgery in group B. In both groups electrosurgery was used for achieving haemostasis. Scalpel dissection was carried out using No 22 Blade and Electrosurgery was set on a cutting mode of 40Units. All patients were given antibiotic prophylaxis half hour before surgery according to institutional protocols. Wound closure at the conclusion of the surgical procedure was done using 2-0 Vicryl for subcutaneous tissue and 2-0 Ethilon or surgical clips for skin. Patients were followed up postoperative for 10days to decide on wound outcomes. Wound outcomes were assessed on Day 3,5 and 10 by resident doctor unaware of the method used for incision to avoid bias. During the follow up assessment was done for both groups with respect to following findings Erythema formation, Serous discharge, purulent exudate, separation of deeper tissues, Isolation of bacteria, Stay of the patient beyond 14 days due to wound infection

Statistical analysis for the data was done using SPSS Version17.0. with Chi-Square test. P-Value was calculated for each observed finding in each group to determine significance. It was compared among both the groups.

Approval was taken from the institutional ethics committee

\section{Results}

Total sample size was 220 patients with 110 patients in each group. The descriptive results of the study has been summarized in Table 1.Using chi-square test $\mathrm{p}$ value was calculated for each factor in both groups. It was found that $\mathrm{p}$ value was significant for occurrence of erythema in both groups on Day3 and Day5. P value was not found significant in other parameters in both groups. Among both groups there were total of six patients three in each group who had to stay in the hospital for more than 14 days due to wound gaping for which secondary wound suturing was done. Patients were discharged after complete wound healing.

\section{Discussion}

In our study we compared the wound outcome between scalpel and electrosurgery for skin and subcutaneous incision. Wound healing is a complex process that proceeds from coagulation and inflammation through fibroplasia, matrix deposition ,angiogenesis, epithelialization ,collagen maturation (deposition of insoluble collagen within the wound surface)and finally wound contraction 10.we studied equal number of patients in both scalpel and electrosurgery group and followed up the patient with respect to wound healing on day 3 , day 5 and day 10 wherein wound was inspected based on Erythema formation ,Serous discharge, purulent exudate, separation of deeper tissues,

Isolation of bacteria, Stay of the patient beyond 14 days due to wound infection. We found that all wounds were healed well and equally resistant to application of lateral traction on wound edges. That means that local thermal injury caused by diathermy did not result in either increased tissue damage or excessive scarring. In fact, acceleration of wound healing process and increased wound strength after full-thickness skin incision by using high-temperature laser beam has been reported in animal models11." Yet, although not confirmed in clinical practice, in vitro studies suggest that the application of intermittent radiant warming results in stimulation of fibroblast growth.[12[.

With the exception of 3 patients who presented with postoperative stay for more than 10 days due to pus discharge from the wound, culture growth showing streptococci, wherein secondary suturing of the wound had to be done ,infectious complications were absent in our series. Figure 1,2, 3, 4 shows comparison between electrosurgery and scalpel wound outcome.

Franchi et al. in a multicenter collaborative trial on midline laparotomy patients found no increase in the early or late wound complications using electrosurgery[12]. Our study showed no advantages of scalpel 
incision over diathermy incision in midline laparotomy diathermy and can be used as an effective alternative to scalpel incision. The present study showed no statistically significant differences in the rate of postoperative complications and postoperative hospital stay between the two groups which is in consistent with other trials [1, $4,13]$.

These results confirm the current belief that extent of tissue damage and risk of septic complications are not influenced by the application of excessive heat produced by the diathermy electrode. On the contrary, it has been suggested that local tissue heating increases subcutaneous oxygen tension, thus enhancing the resistance of the surgical wounds to infection[14].

\begin{tabular}{|c|c|c|c|c|}
\hline Parameter & & & Absent & Present \\
\hline \multirow[t]{6}{*}{ Erythema } & Scalpel & Day 3 & $93.6 \%$ & $6.4 \%$ \\
\hline & & Day 5 & $94.5 \%$ & $5.5 \%$ \\
\hline & & Day 10 & $100 \%$ & $0 \%$ \\
\hline & Electrosurgery & Day 3 & $92.7 \%$ & $7.3 \%$ \\
\hline & & Day 5 & $93.6 \%$ & $6.4 \%$ \\
\hline & & Day 10 & $99.1 \%$ & $0.9 \%$ \\
\hline \multirow[t]{6}{*}{ Serous Discharge } & Scalpel & Day 3 & $98.2 \%$ & $1.8 \%$ \\
\hline & & Day 5 & $98.2 \%$ & $1.8 \%$ \\
\hline & & Day 10 & $100 \%$ & $0 \%$ \\
\hline & Electrosurgery & Day 3 & $99.1 \%$ & $0.9 \%$ \\
\hline & & Day 5 & $95.5 \%$ & $4.5 \%$ \\
\hline & & Day 10 & $99.1 \%$ & $0.9 \%$ \\
\hline \multirow[t]{6}{*}{ Purulent Exudate } & Scalpel & Day 3 & $100 \%$ & $0 \%$ \\
\hline & & Day 5 & $97.3 \%$ & $2.7 \%$ \\
\hline & & Day 10 & $100 \%$ & $0 \%$ \\
\hline & Electrosurgery & Day 3 & $100 \%$ & $0 \%$ \\
\hline & & Day 5 & $97.3 \%$ & $2.7 \%$ \\
\hline & & Day 10 & $98.2 \%$ & $1.8 \%$ \\
\hline \multirow[t]{6}{*}{ Separation of Deep Tissue } & Scalpel & Day 3 & $100 \%$ & $0 \%$ \\
\hline & & Day 5 & $97.3 \%$ & $2.7 \%$ \\
\hline & & Day 10 & $99.1 \%$ & $0.9 \%$ \\
\hline & Electrosurgery & Day 3 & $100 \%$ & $0 \%$ \\
\hline & & Day 5 & $97.3 \%$ & $2.7 \%$ \\
\hline & & Day 10 & $98.2 \%$ & $1.8 \%$ \\
\hline
\end{tabular}

\section{Conclusion}

Results presented with the study showed no significant difference in post op wound infection rates or scar cosmesis in scalpel and electrosurgery group. The traditional fear of excessive tissue devitalisation and poor wound healing were not reflected in this study. Furthermore the recent increase in blood borne diseases such as hep B and C, HIV makes exclusion of scalpel from the operative field an attractive option. Electrosurgical incision of all abdominal layers is safe and expedient technique that can be made useful in patients requiring rapid incision with bleeding diathesis. Hence its left to the surgeons choice to choose scalpel or electrosurgical incision for skin and subcutaneous tissue.

\section{Acknowledgement}

I acknowledge the support given by the Head of the Department, Dept. of General Surgery KMC Mangalore. I acknowledge the support given by the Dept. of General Surgery KMC Mangalore and Manipal University, India for conducting the study.

I acknowledge the support given by the participating patients and relatives in conducting the study.

\section{References}

[1]. Shivagouda P, Gogeri B.V., Godhi A.S., Metgud S.C. Prospective randomized control trial comparing the efficacy of diathermy incision versus scalpel incision over skin in patients undergoing inguinal hernia repair. Recent Research in Science and Technology 2010, 2(8): 44-47

[2]. Cushing H. Electrosurgery as an aid to the removal of intracranial tumors with a preliminary note on a new surgical current generator. Surg GynecolObstet 1989, 64:47:751-84.

[3]. Leaper DJ. Basic surgical skills and anastomosis. In: Russell RC, Williams NS, Bulstrode CJ. Editors. Bailey and Love's Short Practice of Surgery. 24th ed. London. Arnold; 2004,95-106.

[4]. Siraj A, Farooq-Dar M, Gilani AB, Raziq S. Elective midline laparotomy: Comparison of diathermy and scalpel incisions. Professional Med J. 2011, 18(1): 106-111

[5]. Duxbury MS, Blake SM, Dashfield A, Lambert AW. A randomized trial of knife versus diathermy in pilonidal disease. Ann R Coll Surg Eng 2003, 85: 405-7 
[6]. Sheikh B: Safety and efficacy of electrocautery scalpel utilization for skin opening in neurosurgery. Neurosurg 2004, 18:268-72. INCISIONS ELECTIVE MIDLINE LAPAROTOMY;

[7]. Laughlin SA, Dudley DK. Electrosurgery. ClinDermatol 1992, 10:285-90CO

[8]. Sigel B, Dunn MR. The mechanism of blood vessel closure by high-frequency electrocoagulation. Surg GynecolObstet 1965, 121:823- 31

[9]. Kumar V, Tewari M, Shukla HS. A comparative study of scalpel and surgical diathermy incision in elective operations of head and neck cancer. Indian J Cancer 2011, 48:216-9MP

[10]. Cuschieri A, Steele RJ. Surgical craft and technology. In: Cuschieri A, Steele RJ, Moossa AR. editors. Essential Surgical Practice Vol 1. 4th ed. Oxford: Butterworth- Heinemann 2000, 37-68.

[11]. Lodhi FB, Asrar R, Akram M, Hussain R. Incidence of Abdominal Wound Dehiscence (Midline Vs Paramedian Incision Closed With Vicryl No.1). King Edward med Coll 2001,7:38-40

[12] M. Franchi, F. Ghezzi, P.L. Benedetti-Panici, et al., Multicentre collaborative study on the use of cold scalpel and electrocautery for midline abdominal incisions, Am. J. Surg. 181 (2001) 128e13

[13] Siraj A, Farooq-Dar M, Gilani AB, Raziq S. Elective midline laparotomy: Comparison of diathermy and scalpel incisions. Professional Med J. 2011, 18(1): 106-111

[14] Ikeda T, Tayefeh F, Sessler DL et al. Local radiant heating increases subcutaneous oxygen tension. Am J Surg I998;175: 33-7.

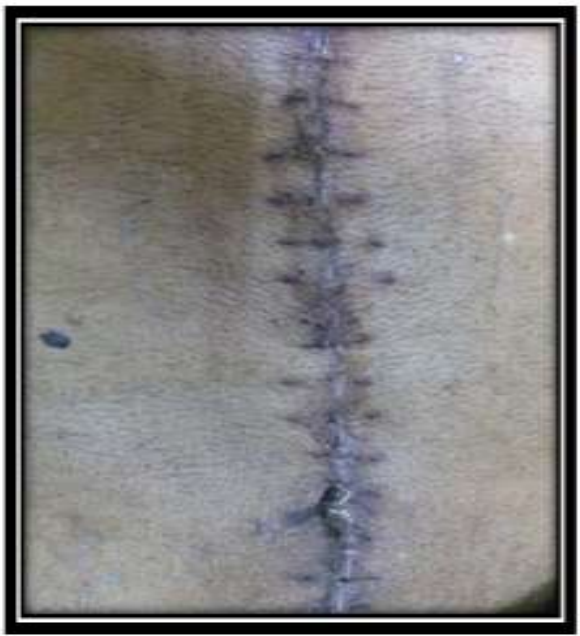

Figure 1. Electrosurgical Incision Abdomen

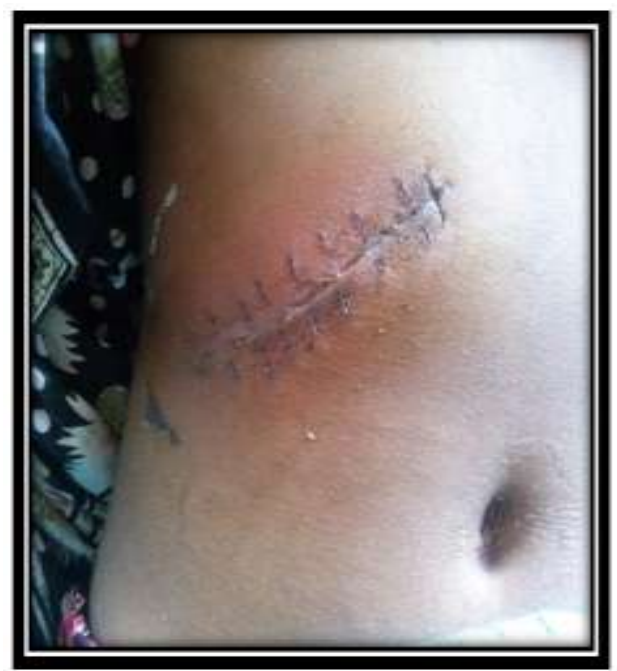

Figure 3. Electrosurgery Incision

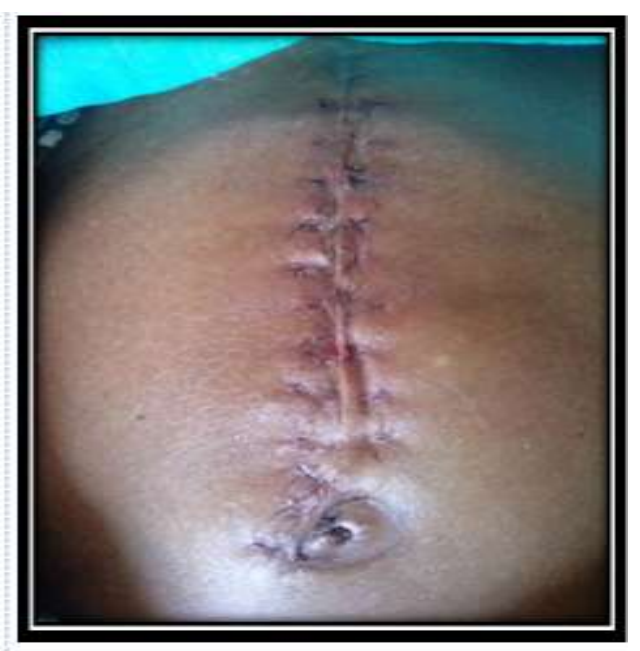

Figure 2. Scalpel Incision Abdomen.

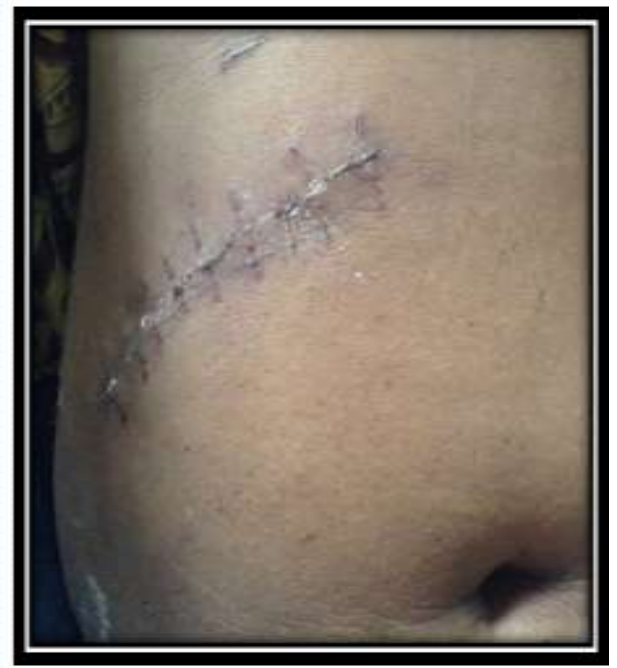

Figure 4_ Scalpel Incision 